\title{
Narrativa de Viagens: Espaços Não Formais de Educação (Des)Encantando a Formação Inicial de uma Professora de Biologia $^{1}$
}

(Travel Narrative: Non Formal Spaces of Education (Dis)Enchanting the Initial Formation of a Biology Teacher)

\section{MARIANE SCHMIDT e LUCIA ESTEVINHO GUIDO}

Universidade Federal de Uberlândia (marianessh@gmail.com, lestevinho@gmail.com)

Resumo. O texto discute a vivência de uma professora em formação inicial em espaços não formais de educação. Acompanhada de professores da escola básica em vários passeios / visitas à museus de Ciência e de Arte, a professora em formação inicial se encanta com as diversas linguagens e conexões entre Ciência e Arte e escreve uma narrativa. A escrita provoca pensamentos que contribuem para que sua formação docente seja significada por linguagens visuais, artísticas, sensoriais e emotivas, além da linguagem científica.

Abstract. The paper discusses the experience of a teacher in initial development in non-formal education spaces. Followed by basic school teachers in several tours / visits to Science and Art Museums, the teacher in initial formation is fascinated with the diverse languages and connections between Science and Art and writes a narrative. The writing induces thoughts that contribute to a teacher training meant through visual, artistic, sensorial and emotive languages, apart from scientific language.

Palavras-chave: ciência, arte, formação inicial de professores

Keyword: science, art, teacher's initial development

\section{Palavras iniciais}

No cenário contemporâneo da sociedade globalizada, os alunos da escola atual encontram dificuldades em lidar com o conhecimento científico. Este é apresentado não apenas pelos livros didáticos, pelos currículos escolares, mas encontra-se disseminado em vários artefatos midiáticos que invadem o cotidiano das pessoas. Consideramos que estes artefatos podem ser pensados como dispositivos, sendo este definido por Giorgio Agamben (2009, p. 42) como "uma máquina que produz subjetivações [...]" e que nos dias de hoje "não há um só instante na vida dos indivíduos que não seja modelado, contaminado ou controlado por um dispositivo". Mas, como adverte o autor, de nada adianta destruir os dispositivos ou "usá-los de maneira correta" sendo esta última, uma ideia ingênua. Acreditamos ser necessário conhecer, olhar, se deter, se envolver com os dispositivos, com os artefatos culturais.

Este texto apresenta a narrativa de uma professora de Biologia em formação inicial que olha, se detém em fotografias produzidas por ela e por professores da educação básica para compor uma narrativa sobre espaços não formais de educação. Os

\footnotetext{
${ }^{1}$ Apoio financeiro da CAPES - Coordenação de Aperfeiçoamento de Pessoal de Nível Superior - Brasil; Programa Novos Talentos - UFU.
} 
professores em formação inicial e continuada foram convidados a conhecer museus de Ciência, Museus de Arte, e, assim, quando diante dos vários dispositivos, foram observados em suas ações, reações, emoções, encantamentos.

Concordamos com Érica Speglich (2012) quando afirma que Ciências também se aprendem no mundo (na televisão, anúncios publicitários, no cinema, na internet). A autora vai além quando comenta que a ciência está conectada com a arte, especialmente por dois motivos, um deles seria a criação do conhecimento científico, que por ser uma “criação" está munida do elemento artístico; o segundo motivo, que nos interessa neste artigo, está no fato de que a obra de arte pode também divulgar a ciência. Nas palavras da autora:

\begin{abstract}
O segundo aspecto diz respeito a um grande número de produções artísticas que se valem de elementos vindos das ciências e que podem nos auxiliar a pensar sobre e com as ciências e as disciplina escolares ciências e biologia em seus aspectos recorrentes e cotidianos. [...] Tais obras podem ser estudadas e analisadas como uma possibilidade de divulgação e ensino das ciências que não toma a explicação como seu foco central. Entretanto, abrem uma ampla gama de possibilidades de discussão do fazer científico, do papel das ciências no mundo contemporâneo e das diferentes formas por meio das quais podemos dizer das ciências (SPEGLICH, 2012, p. 18).
\end{abstract}

Munidas das questões apresentadas por Speglich (2012), voltamos nossa atenção para a necessidade dos professores em formação inicial e continuada de conhecerem, estudarem, apreciarem, fruirem os espaços não formais de divulgação científica, como museus, centros de ciências, e, além desses espaços tradicionalmente visitados pelas aulas de ciências e biologia, os espaços de artes como museus de arte, exposições e instalações artísticas.

Professores em formação inicial e continuada e fazendo parte do Projeto "Mais Ciência, Cultura e Integração: uma parceria universidade, escolas públicas e museus"2 foram envolvidos em atividades que visavam promover, ampliar a experiência cultural. Para isso várias viagens foram planejadas $^{3}$ para conhecer/experienciar museus, exposições, natureza, arte, educação. No passeio, o estudo, as conversas, as lembranças, instantes registrados na máquina fotográfica. Após o passeio, a revelação, o olhar, a seleção. Fotografias produzidas pelos professores compõem álbuns em um grupo do Facebook. As fotografias são revisitadas por uma professora de Biologia em formação inicial para que as mesmas inspirem a contar histórias.

\footnotetext{
${ }^{2}$ Programa Novos Talentos - CAPES / 2288 / 2013/ Processo no. 23038.004583/2013-49.

${ }^{3}$ As cidades escolhidas foram São Paulo, Belo Horizonte e Rio de Janeiro.
} 
O trabalho proposto para os professores foi o de colecionar fotografias. Álbuns que pudessem ser expostos em vários ambientes - reais e virtuais, palestras, conversas, redes sociais. Para ver, refletir, contaminar. O trabalho de Susan Sontag (2004, p. 13) nos auxiliou no pensar fotografar, colecionar, conhecer: "Colecionar fotos é colecionar o mundo". Ainda baseado na autora pensamos que as fotografias permitem várias exposições, que provocam marcas e rasuras, que envelhecem e perdem a cor. Um jogo de cor e sombras que nos convida a brincar, reconhecer, conhecendo com o lúdico. Nas palavras da autora:

\begin{abstract}
As fotos que brincam com a escala do mundo, são também reduzidas, ampliadas, recortadas, retocadas, adaptadas, adulteradas. Elas envelhecem, afetadas pelas mazelas habituais dos objetos de papel; desaparecem; tornamse valiosas e são vendidas e compradas; são reproduzidas. Fotos, que enfeixam o mundo, parecem solicitar que as enfeixemos também. São afixadas em álbuns, emolduradas e expostas em mesas, pregadas em paredes, projetadas como dispositivos. Jornais e revistas às publicam; a polícia às dispõem em ordem alfabética; os museus as expõem; os editores às compilam (SONTAG, 2004, p. 15).
\end{abstract}

Foi assim que as fotografias produzidas e revisitadas pelos professores e professoras trouxeram significados do que seria o trabalho docente, de como podemos e somos educados/tocados por imagens e memórias. Poderia a fotografia construir uma "crônica visual" do ser docente? Tal qual a crônica visual construída pela família através da fotografia a ponto do álbum fotográfico familiar ser um item fundamental do acervo familiar. "Por meio de fotos, cada família constrói uma crônica visual de si mesma [...] Esses vestígios espectrais, as fotos, equivalem à presença simbólica dos pais que debandaram. Um álbum de fotos de família é, em geral, um álbum sobre a família ampliada - e, muitas vezes, tudo o que resta dela" (SONTAG, 2004, p. 19). Seria este o mesmo sentido das fotos que revelam a construção da docência?

Roland Barthes em "A Câmara Clara” inspira:

\begin{abstract}
“[...] O que a fotografia reproduz ao infinito só ocorre uma vez: ela repete mecanicamente o que nunca mais poderá repetir-se existencialmente. Nela, o acontecimento jamais se sobrepassa para outra coisa: ela reduz sempre o corpus de que tenho necessidade ao corpo que vejo; ela é o Particular absoluto, a Contingência soberana, fosca e um tanto boba, o Tal (tal foto e não a Foto), em suma a Tique, a Ocasião, o Encontro, o Real, em sua expressão infatigável" (BARTHES, 1984, p. 13).
\end{abstract}

Assim entendemos a construção do Álbum de fotografias, seja um álbum de família, seja um álbum do ser professor, um álbum que registra viagens do professor, que revela a construção do sujeito enquanto um ente do mundo, da profissão, do eu lírico, que se inspira ao sair para conhecer o mundo. E esta inspiração inscrita nas 
fotografias e no álbum inspira a professora de Biologia em formação inicial a escrever, narrar histórias vividas por professores e professoras que ficaram adensadas nas imagens, nos álbuns de fotografias e que carregam significados do próprio estado de ser docente, ser liberto para outros olhares, focar a ciência, a arte, a cultura. Viajar por espaços artísticos, científicos e culturais inspiram a viagem narrativa de olhar que encanta desencantando a formação docente.

Somos mobilizadas também por Barthes (1984, p. 16) quando expressa que olhar fotografias é tarefa arriscada, pois: “[...] Seja o que for o que ela dê a ver e qualquer que seja a maneira, uma foto é sempre invisível: não é ela que vemos. [...] Em suma, referente adere. E essa aderência singular faz com que haja uma enorme dificuldade para acomodar a vista à fotografia". Assim os álbuns de fotografias e cada fotografia tocada pela professora em formação inicial transfiguram-se em singularidades que compõem a narrativa, uma narrativa das viagens.

\section{Narrativa de viagens de uma professora de Biologia em formação inicial}

Estive pensando sobre como começar esta história. Talvez o início seja a parte mais difícil de uma escrita, o tempo a ser respeitado, a demora em sentir a inspiração mover os dedos sobre os teclados e afagar o pensamento. Mas, por que não começar com uma pergunta? Não com uma pergunta qualquer, mas uma pergunta que conte um pouco sobre o que intenciona esta história. Uma pergunta nem simples, nem complexa. Uma pergunta que entregue uma ideia, e nos permita divagar: $O$ que significa um museu? E, antes que cada um de vocês comece a matutar tentando chegar precisamente a uma resposta, tenho algumas experiências a compartilhar.

\section{Início}

Estamos em São Paulo. Sim. A selva de pedra do Brasil. Aquele lugar, onde você sempre vê aquele "mar de gente" pela $T V$. Onde parece que tudo acontece: notícia, nascimento, pesquisa, produção, trânsito, tragédia. Mas não viemos até aqui por qualquer coisa. Não! Viemos aqui para conhecer. 
Amélia $^{4}$ dirige seu olhar para o chão. No chão há palavras. Letras reluzentes que se destacam em superfície negra. Palavras, frases, versos, poemas. Amélia não está sozinha. Vejo outras pessoas olhando para baixo, caminhando, conversando e fotografando o que lhes chama atenção. Logo a sala está quase vazia: alguns saem mais rapidamente, e outros aproveitam seu tempo no espaço. Agora um corredor. Grandes janelas de um lado, parede branca do outro. A parede está cheia de letrinhas que se destacam em preto. Letrinhas que formam palavras, frases, versos e poemas. No corredor, novamente pessoas: que observam, que comentam, que fotografam e posam com a parede. Sofia conta alguma coisa para Helena, apontando para a parede, como se mostrasse algo que despertou sua atenção. Amélia se dirige a mim e diz algo assim: “Olhe, é este poema que adorei. Você pode fotografar para mim?" A quem possa interessar, o poema é o que se segue:

\section{QUALQUER AMOR}

Só se pode viver perto de outro, $e$

Conhecer outra pessoa, sem perigo de

Ódio, se a gente tem amor. Qualquer

Amor já é um pouquinho de saúde, um

Descanso na loucura.

(João Guimarães Rosa, excerto de Grande Sertão: Veredas (1956)).

Da Pinacoteca ${ }^{5}$ sei que era bela. De fora e de dentro. Prédio imponente. Cartão postal! Da ponte que havia lá dentro, olhava para os lados e via grandiosidade. Depois da ponte um jardim. Jardim inusitado, plantas pequeninas penduradas por finíssimos fios transparentes, e pareciam flutuar em brancos vasos de cerâmica de formas variadas. Tocar não era permitido. Quase nada ali podia ser tocado, e pouco podia ser fotografado. E o que significa tocar ou fotografar um espaço como este? Seria uma necessidade? Ou uma vontade? Seria atestar uma experiência? Ou recusá-la? Seria olhar? Ou desviar o olhar? Registrar para quê? Mostrar? Compartilhar? Refletir? Para quê?

\footnotetext{
${ }^{4}$ Nome fictício de uma das professoras da educação básica. Todos os nomes na referida história são fictícios conforme projeto de pesquisa intitulado "Ciência, cultura e arte: um estudo a partir dos registros fotográficos de professores da Educação Básica", aprovado pelo Comitê de Ética em Pesquisa (Parecer n. $862784)$.

${ }^{5}$ Pinacoteca do Estado de São Paulo.
} 
Havia salas repletas de quadros, todos possuíam uma linha desenhada ao chão indicando o limite até onde era permitido chegar para observar as obras. Nessas salas, tentava entender alguns quadros, lia descrições, olhava de cá e olhava de lá. Outros eu só via, e seguia em frente. Havia uma sala escura com estruturas dispostas pelo chão, que escondiam lâmpadas acesas. As estruturas rodavam e rodavam, desenhando com luz o espaço, as paredes, o teto, o chão e as pessoas.

Visitei um recinto escuro iluminado apenas por luzes negras. Tudo o que se via à porta eram linhas construindo formas geométricas que pairavam no ar. Parecia ficção científica. Entramos e nos vimos azuis e cintilantes. Entramos e tocamos as linhas que construíam as formas. Elas vibraram.

E também, uma sala de espelhos. Espelhos compridos que escondiam as paredes, sequências de espelhos redondos, de tamanhos diversos, pendurados quase alcançavam o chão. Ali havia interação. Ali eu podia tocar, e podia fotografar. E fotografei. Fotografei o reflexo de outras pessoas. Fotografei o meu reflexo. Fotografei outras pessoas fotografando seus próprios reflexos. Sozinhas e em grupo. Alice, Sabrina, Isabella e Thales estavam lá. Exploramos posições. Brincamos com nossos reflexos. Desconstruímos e reconstruímos nossos corpos.

Entramos em outro mundo ${ }^{6}$. Senti as leis da física. Presenciei fenômenos que pareciam improváveis. Quase como mágica. Fenômenos que nos cercam, regem nossas vidas todos os dias sem que sejam lembrados, e eu aprendi. Corpos celestes pareciam mais próximos do que nunca. Toquei em um meteorito, fiz observações astronômicas, vi o Sol e a geologia da Terra. Relevos, latitude e longitude. Passei pelo Cerrado, Amazônia, Mata Atlântica, Caatinga e Pantanal. Conheci a árvore da vida. Evolução, adaptação, diversidade. A vida no céu, no oceano, e no continente. Vida presente e vida passada. História de vida.

Havia tanto espaço naqueles espaços. Lembro de me encantar pelo muro que separava o prédio do Museu da Língua Portuguesa da avenida em frente. Era um muro amarelo, com sombras de crianças em um jogo de futebol e emoldurado por tijolos à vista. Lembro-me de fotografá-lo, e do contraste entre o amarelo e o azul que pintava o céu. Lembro-me de estarmos em época de Copa do Mundo. Lembro-me da cidade, da arquitetura do cimento e do metrô. Da Luz, do Mercado, da comida e da noite.

\footnotetext{
${ }^{6}$ Catavento Cultural e Educacional.
} 


\section{Meio}

Jamais imaginei existir um lugar como este tão perto de mim. Combinação de flora, fauna e arte ${ }^{7}$. A arte entrelaçada à natureza. Natureza é arte e arte é natureza na essência. Um lugar onde não são os fins que justificam os meios, mas caminhos que não precisam de justificativa porque são o que são, porque tudo é beleza. E em cada espaço que se entra, se é convidado a trancar as portas, e se desligar do mundo que não faz parte do momento, porque o momento é tudo que importa, é único e é experiência.

Recordo das caixas de som elevadas à altura das pessoas que entravam no espaço. Todas dispostas formando um grande círculo em torno de bancos de madeira. Ao entrar, o que se ouvia era um coro, uma melodia composta por nada mais que vozes humanas. Porém, quando se passava por cada caixa, a impressão era que, bem ali, a sua frente, alguém cantava. Algumas pessoas sentavam, outras não. Algumas conversavam, ou comentavam, e outras permaneciam em silêncio. Interessante nunca antes ter visitado uma obra cujo som seria seu principal artifício.

Outra obra sonora estava em um grande galpão. Paredes e teto cheios de algo parecido com espumas. Caixas de som penduradas por todo o lugar, e várias cadeiras ao centro. O grupo se dispõe a sentar. Em alguns momentos da história contada pela voz que vinha das caixas, as pessoas a acompanhavam através do roteiro disponível no espaço. Alice fecha os olhos enquanto ouve. Parte do grupo permanece até o fim da história. Era uma voz feminina, e um relato de desespero. Eu ouvia vagões passando, ferramentas trabalhando, correntes se arrastando, homens cantando. Tudo acontecia ao meu redor.

Entramos em uma sala onde tudo era vermelho. Tapetes vermelhos sob os pés. Armários, roupas, sofá, almofadas, televisão, quadros, livros, estantes, cadeiras, lixeira, garrafas, geladeira, ventiladores, xícaras, espelhos, abajour, relógios, aquário, vasos com flores vermelhas. Um corredor escuro, um fluido vermelho derramado sobre chão e um ruído de gotas pingando ao longe levam a uma pia suja com líquido vermelho. Voltando pelo mesmo caminho tenho a impressão de que sensações foram forjadas. É tudo o que parece ser?

Um prédio cinza e retangular parece flutuar em meio a um pequeno lago de água extremamente azul e colinas intensamente verdes. É possível ver seu reflexo no lago. Dentro do prédio, azulejos brancos guardavam coisas vermelhas parecidas com vísceras

\footnotetext{
${ }^{7}$ Instituto Inhotim localizado na cidade de Brumadinhho, MG.
} 
que se empilhavam, uma em cima da outra, se entrelaçavam, se misturavam: órgãos, ossos e carne. Subindo as escadas grandes azulejos desenhados em azul envolviam as paredes e pareciam preencher com leveza e suavidade o ambiente. Ouço alguém dizer: "Isto aqui é mais interessante". Lá de cima era possível olhar para baixo. E ouço alguém chamar: "Venha ver daqui de cima!". Olhando para cima, o que se via eram plantas carnívoras desenhadas na mesma direção do monte de vísceras que estava lá em baixo. Uma obra, diferentes ângulos.

Deparamo-nos com outro grande prédio cinza. Deixamos os sapatos na porta. Entramos descalços. Lá dentro, cortinas escondiam o que quer que existisse por trás. A primeira cortina revelou algo que me pareceu improvável: uma piscina. Iluminada com luzes azuis, envolta por um deck de madeira e colchonetes. Carolina e outras quatro pessoas, arregaçaram as barras de suas calças, e sentadas à beira da piscina, mergulharam os pés na água. Conversando, lá permaneceram por um tempo.

Ao atravessar a próxima cortina, vimos vários colchões e travesseiros azuis espalhados pelo chão. Tudo era escuro, a não ser pelas projeções carimbadas em duas paredes opostas, do chão ao teto, que exibiam algumas cenas. Todos nos deitamos por um instante. Descansando ou divagando. Na terceira sala, redes coloridas. Azuis, amarelas, vermelhas. Deitaram-se, balançando de olhos fechados ou de olhos abertos. Faces serenas ou faces sorridentes. Mais uma vez, a única luz vinha das projeções que estampavam todas as paredes. As projeções eram moldadas com o balanço dos corpos. Os corpos nas redes eram sombras nas paredes. Era tudo uma viagem.

No Inhotim, vi uma árvore flutuante. Se me posicionava sob ela, ao olhar para cima, via as ramificações de suas raízes. Um jardim imenso com vasos em forma de letras, palavras sendo construídas e registradas. Pessoas compondo um caleidoscópio no topo de uma colina viam mil e uma faces. Posei com três carros coloridos que diziam: "É nobreza fazer boné"; "E o bolero borel oboé”; "Zé Deserto, três é dez" (lê-se, também, de trás para frente). E naquele dia todos os sentidos foram estimulados, a sensibilidade aguçada, a fuga da rotina, o contato com o inesperado e a compreensão do indecifrável.

$\mathrm{Na}$ Liberdade $^{8}$ todo tempo era pouco. Era pouco para explorar cada artefato, pouco para apreciar as intenções de cada espaço e pouco para conhecer as histórias impregnadas nas colunas de cada prédio que cercava a praça. Havia tanta história em

\footnotetext{
${ }^{8}$ Praça da Liberdade situada no bairro dos Funcionários na cidade de Belo Horizonte, MG.
} 
um só lugar, e sempre era a história se apresentando através da arte. A História de Minas Gerais na capital de Minas Gerais.

A Geografia da Memória de Minas Gerais estampada em uma parede de museu ${ }^{9}$ continha recados que representavam suas cidades. Eram escritas de poetas coladas em um mapa. Coromandel: "Os caminhos estão descansando"; João Pinheiro: "O primeiro ar da manhã chama os cheiros da cidade que desperta"; Itamarandiba: "Por toda parte sentir o segredo das coisas vivas". As Vilas Mineiras reproduzidas em miniatura possuíam casinhas, portinhas, janelinhas e igrejinhas. Todas as estruturas faziam imaginar quem sairia e quem entraria em cada uma das portinhas. Quem estaria caminhando pelas pequenas ruazinhas das Vilas Mineiras?

Vi os objetos da Fazenda Mineira. Como era detalhada e original esta fazenda. Todos os utensílios, instrumentos, ferramentas, móveis e artigos de ornamentação que se possa imaginar estavam ali, presos nas paredes, à iluminação baixa, tudo pintado de uma única cor. Seria esta a Fazenda Mineira do imaginário? Aquela que evoca tradições, inspira poemas e infunde a curiosidade de conhecer mais?

Conheci os Caminhos e Descaminhos que a recortavam e interligavam; As possibilidades atribuídas por seu relevo, águas e natureza; O Povo Mineiro todo misturado; A Minas Rupestre como um conto de outros tempos; A Família Mineira, seus costumes e suas crenças; Fatos da Inconfidência e poesias dos poetas. Foi então que percebi todo o encantamento do que é uma cultura representada pela arte.

\section{Fim}

Chegar foi quase inacreditável. Pelo menos para mim que nunca tinha estado lá antes, e imagino que muitos outros neste grupo tenham compartilhado a sensação de conhecer um lugar pela primeira vez. Estar pela primeira vez em qualquer lugar que seja, já tende a ser uma experiência bastante relevante, mas, conhecer o Rio de Janeiro pela primeira vez é coisa que não se esquece. E diziam que era maravilhosa. Sem entender o porquê, a gente quase não acredita. Mas ela é natureza e é concreto. É brisa do mar e fumaça de carro. É caminhar na orla da praia e pedir uma cerveja num bar de esquina.

Memórias do encontro entre biologia e sociedade no Instituto Fiocruz. Peças que nos levam a outros tempos, narram o passado, ensinam com bom humor. Reproduções

\footnotetext{
${ }^{9}$ Memorial de Minas Gerais Vale localizado na Praça da Liberdade, Belo Horizonte, MG.
} 
do corpo humano em larga escala, click incessante. Quão interessante é ver através das lentes de um microscópio?

Então no MAR $^{10}$ entramos e no MAR fomos acolhidos com histórias da cidade. Lá havia sobreposições do velho, do novo e do que ainda estava em construção. Lá havia sobreposições de belas histórias e de histórias não tão belas assim. Mas tudo era a história da cidade. E nem tudo já era história. Algumas histórias ainda são presente.

Representações que aparentam transbordar realidade são aquelas que fotografamos tão avidamente, e ponto. Estas representações são belas, mas não existem para serem belas. Clamam por reconhecimento. Clamam desesperadamente por compreensão, atenção e atitude. E nós notamos. Nós fotografamos. Nós compartilhamos. E ponto.

Vejo um grupo de crianças assistindo a uma videoinstalação. Sofia se aproxima, também observando ao vídeo, e após alguns minutos se dirige a um dos pequenos, propondo conversa e questionamento. As pessoas caminham lentamente pelo espaço. Escuto exclamações do tipo: "estou tentando entender o que é isto aqui". Pessoas que aproveitam o tempo. Pessoas com curiosidade para experimentar. Pessoas que voltam para ler descrições. Pessoas que se propõem a participar da obra de arte. Pessoas que compartilham descobertas e percepções dentro do espaço. Pessoas querendo deixar sua marca.

Tudo o que havia naqueles espaços era contado com destreza. Da rota dos escravos à criação das favelas. Do que o passado carrega de podre, ao que carrega de belo. Das colas, às escolas. Do giz gasto todos os dias às significações desperdiçadas por falta de oportunidade. Da diversão ao castigo. Das escolas que são gaiolas às escolas que são asas. A realidade pelas mãos do artista e o artista esculpido pela realidade. Modos de vida, de prazer e de sofrer. Fuga da dissimulação. Tudo tinha uma potência: arte, educação, cultura.

\section{$[\ldots]$}

\section{Palavras finais}

O processo de construção desta narrativa de viagem não ocorreu de forma superficial. Ele abrange as vivências da professora em formação inicial, como se elas fossem mediadas pelas visitas ocorridas durante as viagens. Primeiramente: observar,

\footnotetext{
${ }^{10}$ Museu de Arte do Rio, localizado na região do Centro da cidade do Rio de Janeiro.
} 
fotografar e experienciar os espaços e as relações concebidas entre professores e artefatos científicos, artísticos, culturais. Buscar entender, atentando-se a atitudes e comentários, entrelaçando a essência de cada obra ao que pode comunicar cada uma destas observações. Em segundo lugar: reviver, refletir e ressignificar as descobertas conquistadas, através de uma imersão nas memórias, naquilo que permanece.

Todo este processo faz evocar um tornar-se professor atravessado por sensibilizações, sejam elas causadas pela ciência, pela arte ou pela cultura presente em cada um dos espaços. Seja o que for que desperta nestes professores em formação continuada a vontade de olhar e revelar novos olhares, desperta também uma formação inicial provocada e atravessada por linguagens visuais, artísticas, sensoriais e emotivas capazes de instigar novas significações.

Entrecruzam-se ciência e arte, natureza e cultura. Formas híbridas inundam o íntimo da professora que escreve com palavras sensíveis à sua formação que se completa, que cresce e esquece a ciência separada da arte e do sensível. Quando "olhar através das lentes de um microscópio" se torna mais do que a simples ação, e o microscópio não é apenas aquele que vê/mostra a Ciência, não é apenas um instrumento para facilitar a visualização de um microrganismo qualquer, o processo de olhar através de suas lentes passa a evocar mais: se torna interessante, o olhar passa a buscar algo que já não parece óbvio.

O diário de viagem permite atentar para o que despertam as fotografias que revelam espaços, obras de arte e conexões, entre pessoas, conexões estabelecidas com objetos, consigo mesmo ou com o outro. Este processo possibilita avivar outras leituras de mundo, de cotidiano e descobrir que nem tudo se trata do que é, mas do que pode ser: potência. Atentar para as palavras que irrompem de uma imagem (que não é mais somente isso, é memória e sentimento) é construir-se de fora para dentro e de dentro para fora: o dispositivo que atinge, e transborda.

\section{Referências}

AGAMBEN, G. O que é contemporâneo? E outros ensaios. Trad. por Vinicius Nicastro Honesko. Chapecó, SC: Argos, 2010.

BARTHES, R. A Câmara Clara. Trad. por Júlio C. Guimarães. Rio de Janeiro: Nova Fronteira, 1984.

ROSA, J. G. Grandes Sertões: veredas. Rio de Janeiro: Nova Fronteira, 2001. 
SONTAG, S. Sobre fotografia. Trad. por Rubens Figueiredo. São Paulo: Companhia das Letras, 2004.

SPEGLICH, E. Entresons e educação e divulgação e ciências (e um pouco de arte). In: ENCONTRO NACIONAL DE DIDÁTICA E PRÁTICAS DE ENSINO, 15, 2012, Campinas. Anais... Campinas, 2012, 2 CD-ROM.

MARIANE SCHMIDT. Graduanda em Ciências Biológicas pela Universidade Federal de Uberlândia. É bolsista de Iniciação Científica pelo CNPQ, pesquisa sobre análise de imagens, formação inicial e continuada de professores em espaços não formais de educação. Monitora do Projeto "Mais Ciência, Cultura e Integração: uma parceria universidade, escolas públicas e museus / Novos Talentos / CAPES. Faz parte do Laboratório de Mídias, Museus, Ciência, Cultura e Educação (MMuCCE INBIO/UFU).

LUCIA DE FATIMA ESTEVINHO GUIDO. Possui graduação em Licenciatura Em Ciências Biológicas pela Organização Educacional Barão de Mauá (1986), mestrado (1997) e doutorado (2005) em Educação pela Universidade Estadual de Campinas. Docente do Instituto de Biologia e do Programa de Pós-Graduação em Educação da Faculdade de Educação da Universidade Federal de Uberlândia atuando na formação inicial e continuada de professores de Ciências e Biologia. Pesquisa na área de Educação e Imagens enfocando as seguintes temáticas: Análise fílmica, televisiva e fotográfica e suas conexões com a Educação em Biologia; Mídias, educação e formação docente; Biologia e culturas; Análise de obras audiovisuais que trazem a temática ambiental.

Recebido: 30 de novembro de 2014

Revisado: 30 de março de 2015

Aceito: 12 de abril de 2015 